\title{
Editorial
}

\section{COVID-19 and Maternal Death in Brazil: An Invisible Tragedy}

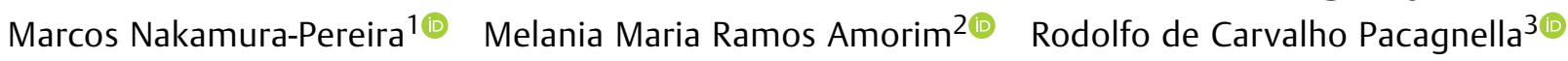 \\ Maira Libertad Soligo Takemoto ${ }^{4(}$ Fatima Cristina Cunha Penso ${ }^{5(}$ Jorge de Rezende-Filho6(i) \\ Maria do Carmo Leal7(1) \\ ${ }^{1}$ Instituto Nacional de Saúde da Mulher, da Criança e do Adolescente \\ Fernandes Figueira, Fundação Oswaldo Cruz, Rio de Janeiro, RJ, Brazil \\ 2 Instituto de Medicina Integral Prof. Fernando Figueira, Recife, PE, Brazil \\ ${ }^{3}$ Universidade Estadual de Campinas, Campinas, SP, Brazil \\ ${ }^{4}$ Faculdade de Medicina de Botucatu, Universidade do Estado de São \\ Paulo, Botucatu, SP, Brazil \\ ${ }^{5}$ Maternidade Leila Diniz, Hospital Municipal Lourenço, Rio de Janeiro, \\ RJ, Brazil \\ 6 Universidade Federal do Rio de Janeiro, Rio de Janeiro, RJ, Brazil \\ 7 Escola Nacional de Saúde Pública Sergio Arouca, Fundação Oswaldo \\ Cruz, Manguinhos, RJ, Brazil
}

Rev Bras Ginecol Obstet 2020;42(8):445-447.

The infection with the new severe acute respiratory syndrome coronavirus 2 (SARS-CoV-2), which is responsible for causing the coronavirus disease 2019 (COVID-19), became a devastating threat to the health of the world population and was declared a global pandemic by the World Health Organization (WHO) on March 11, 2020. Beginning in China at the end of 2019, it quickly spread to several countries, and the first case was officially diagnosed in Brazil on February 26, 2020. Since then, despite initial measures to slow the virus' spread, we are alarmed by the exponential growth in the number of cases. At the time of writing this text, Brazil exceeds 800,000 cases and 40,000 deaths, second only to the United States in those numbers. However, the well-known underreporting of cases and deaths in the country, associated with the incomprehensible decision to suspend access to the Epidemiological Surveillance Information System - Influenza (SIVEP-Gripe, in the Portuguese acronym) database for recalculating the number of deaths makes it difficult to keep these numbers up to date.

The real impact of COVID-19 on pregnancy, childbirth and the puerperium period, and if the pregnancy-puerperal state changes the natural history of COVID-19 are controversial issues that remain to be elucidated. Initial studies in the obstetric population were not suggestive of a greater susceptibility of pregnant women to COVID-19 complications. ${ }^{1,2}$ However, subsequent publications reported cases of pregnant women with severe disease and maternal deaths from COVID-19. ${ }^{3-8}$ A Swedish study showed a higher risk of pregnant women needing admission to the intensive care unit compared with non-pregnant women. ${ }^{7}$ To date, reports of maternal death have been published in Iran and Mexico (seven cases each), in the United Kingdom (five deaths) and in the United States (one case). ${ }^{4-6,8}$

These data raise concerns about the impact of COVID-19 on maternal mortality in Brazil. In April 2020, the Brazilian Ministry of Health included all pregnant and puerperal women and patients with gestational or fetal loss up to day 15 in the risk group for COVID-19. However, until the end of May there was no official release of aggregated death data during pregnancy and postpartum. Amorim et al (2020), ${ }^{9}$ using official and media data, have preliminarily reported 5 cases of maternal death in the country until April 10, 2020. Finally, at the end of May, the Ministry of Health $^{10}$ reported the occurrence of 36 cases of maternal death from COVID-19 and 252 cases of severe acute respiratory syndrome (SARS) occurring up to epidemiological week 21 (May 17-23, 2020). ${ }^{10}$

The identification of these 36 deaths already places Brazil in the leadership of maternal deaths due to COVID-19 in the world, even when adding all maternal deaths published in the literature so far. What would justify so many deaths from COVID-19 in our country? Is it possible that the population of pregnant women has very different characteristics from pregnant women in other countries, and that the presence
Address for correspondence Marcos Nakamura-Pereira, Instituto Nacional de Saúde da Mulher, da Criança e do Adolescente Fernandes Figueira, Fundação Oswaldo Cruz, Av. Rui Barbosa $716,3^{\circ}$ andar-Flamengo, RJ, 22250-020, Brazil

(e-mail: marcosnakamura@globo.com).
DOI https://doi.org/ 10.1055/s-0040-1715138. ISSN 0100-7203.
Copyright $\odot 2020$ by Thieme Revinter Publicações Ltda, Rio de Janeiro, Brazil

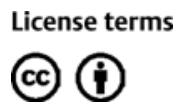


of comorbidities, especially preeclampsia and obesity, which are very common inflammatory conditions in our population and risk factors for complications due to COVID-19, can explain these findings? ${ }^{11-13}$ Hypertension is the leading cause of maternal death and maternal near-miss in Brazil, and there is evidence of a similar picture of preeclampsia observed in women with severe COVID. ${ }^{14,15}$ Data from the Ministry of Health show a higher incidence of hypertension among pregnant women and women who have recently died, compared with those who have had SARS and recovered (13.9\% versus 3.9\%). ${ }^{10}$ Thus, when hypertension and COVID19 infection occur simultaneously in pregnancy, the inflammatory response may contribute to a worse maternal prognosis. Obesity (11.1\% versus $4.4 \%$ ) is another condition of high incidence among fatal cases in Brazil. ${ }^{10}$ Brazil has a high prevalence of overweight and obese pregnant women, ${ }^{16}$ and the metabolic syndrome is also a proinflammatory state, just like the systemic response observed in severe cases of COVID. In France, obesity is a risk factor for severe maternal morbidity and there is no reason to suppose that such an association is not present in Brazil. ${ }^{13}$ In addition, obesity may contribute to maternal death because of its association with preeclampsia. $^{12}$

In Brazil, barriers to access services with specialized care and inadequate monitoring of obstetric complications also persist in hospitals, primary care and specialty clinics, as evidenced in two large national studies. ${ }^{17,18}$ In addition, there are structural deficiencies in Brazilian maternity hospitals, both in physical and in human and material resources (medicines, laboratory, etc.). In the public system, only $15 \%$ of maternity units have an adult intensive care unit (ICU), and the availability of places is extremely uneven across the Brazilian territory. ${ }^{19}$ Consequently, maternal deaths in Brazil are more related to phases II and III of delays ${ }^{17}$ and this was possibly intensified in this pandemic period. In general, for the better management of cases of symptomatic people during the pandemic period, Basic Health Units have postponed prenatal consultations, which has increased the barriers to adequate prenatal care. As a result of this approach, pregnant women have arrived in hospitals in more serious clinical conditions that could have been avoided with timely and quality prenatal care.

These deficiencies in the health system, potentially aggravated by the recent economic crisis and restrictions of public investments in health, are put in check at this moment because all resources and attention are focused on care for the COVID19 pandemic. Roberton et al, in statistical modeling to assess the indirect effects of COVID-19, estimated that maternal mortality could increase between 8.3 and $38.6 \%$ per month in low and middle income countries and that $60 \%$ of this effect could result from the reduction of four essential interventions: parenteral administration of uterotonics, antibiotics, anticonvulsants, and a clean environment for childbirth. ${ }^{20}$

At this moment, it is difficult to measure the impact of the COVID-19 pandemic on maternal mortality in Brazil. The growing figures and media reports will certainty cause an increase in relation to previous years. Brazil has failed to meet the millennium goal of reducing maternal mortality by
75\% from 1990 to 2015, and, since 2012, there has been no sustained reduction in maternal mortality. ${ }^{21}$ We are still far from the goal set by the federal government of 30 deaths per 100,000 live births by 2030 to contribute to the WHO Sustainable Development Goals, a plan to which Brazil is a signatory country.

In the current context of the pandemic, it is essential to continue the usual obstetric care with prenatal care in basic units and maternity units by facilitating pregnant women's access to health services, ensuring essential supplies for hospitals with obstetric care and continuing the services of family planning and abortion provided by law. In this particular matter, we observe with perplexity and concern the revocation of Technical Note number 16/2020 (COSMU/ CGCIVI/DAPES/SAPES/MS), which only ensured access to sexual and reproductive health within the pandemic context (https://kidopilabs.com.br/planificasus/upload/covid19_anexo_46.pdf). Managers should also ensure the rapid identification of pregnant and postpartum women with symptoms suggestive of COVID-19, ideally by offering universal testing $^{22,23}$ and making ICU beds available in a timely manner to avoid delays in proper treatment.

Finally, it is necessary to think about the postpandemic moment. Part of the advanced support equipment acquired by federal entities because of COVID-19 can be reverted to our maternity hospitals later. However, for reducing maternal mortality in Brazil, it is necessary to reduce delays in accessing the health system and receiving adequate, respectful, and quality care. ${ }^{24}$ Recently, the Brazilian Federation of Gynecology and Obstetrics Associations (FEBRASGO, in the Portuguese acronym) Specialized National Commission on Maternal Mortality has contributed to the debate on the reduction of maternal mortality in Brazil by making several proposals ${ }^{25}$ and remains at the disposal of managers to assist in the development of proposals and implementation of actions aimed at improving obstetric care and, consequently, reducing maternal mortality.

The death of a woman in the pregnancy-puerperal cycle is always a tragedy. Maternal death must be considered a preventable tragedy and every effort must be made to prevent it. The lives of pregnant and postpartum women matter!

Conflict of Interests

The authors have no conflict of interests to declare.

Acknowledgment

To the Brazilian Group for COVID-19 and Pregnancy Studies.

\section{References}

1 Chen H, Guo J, Wang C, Luo F, Yu X, Zhang W, et al. Clinical characteristics and intrauterine vertical transmission potential of COVID-19 infection in nine pregnant women: a retrospective review of medical records. Lancet. 2020;395(10226):809-815. Doi: 10.1016/S0140-6736(20)30360-3

2 Chen N, Zhou M, Dong X, Jieming Q, Gong F, Han Y, et al. Epidemiological and clinical characteristics of 99 cases of 2019 novel coronavirus pneumonia in Wuhan, China: a descriptive study. Lancet. 2020;395(10223):507-513. Doi: 10.1016/S01406736(20)30211-7 
3 Breslin N, Baptiste C, Gyamfi-Bannerman C, Miller R, Martinez R, Bernstein K, et al. COVID-19 infection among asymptomatic and symptomatic pregnant women: Two weeks of confirmed presentations to an affiliated pair of New York City hospitals. Am J Obstet Gynecol MFM. 2020;2(02):100118. Doi: 10.1016/j.ajogmf. 2020.100118

4 Hantoushzadeh S, Shamshirsaz AA, Aleyasin A, Seferovic MD, Aski SK, Arian SE, et al. Maternal death due to COVID-19. Am J Obstet Gynecol. 2020;223(01):109.e1-109.e16

5 Knight M, Bunch K, Vousden N, Morris E, Simpson N, Gale C, et al. Characteristics and outcomes of pregnant women hospitalised with confirmed SARS-CoV-2 infection in the UK a national cohort study using the UK Obstetric Surveillance System (UKOSS). medRxiv [Preprint]. 2020:1-22

6 Vallejo V, Ilagan JG. A Postpartum Death Due to Coronavirus Disease 2019 (COVID-19) in the United States. Obstet Gynecol. 2020;136 (01):52-55. Doi: 10.1097/AOG.0000000000003950 [ahead of print]

7 Collin J, Byström E, Carnahan A, Ahrne M. Public Health Agency of Sweden's Brief Report: Pregnant and postpartum women with severe acute respiratory syndrome coronavirus 2 infection in intensive care in Sweden. Acta Obstet Gynecol Scand. 2020;99 (07):819-822. Doi: 10.1111/aogs.13901 [ahead of print]

8 Lumbreras-Marquez MI, Campos-Zamora M, Lizaola-Diaz de Leon H, Farber MK. Maternal mortality from COVID-19 in Mexico. Int J Gynaecol Obstet. 2020;x:13250

9 Amorim MMR, Takemoto MLS, Fonseca EB. Maternal deaths with Covid19: a different outcome from low-to middle- resource countries? Am J Obstet Gynecol. 2020;x:x

10 Boletim Epidemiológico Especial. COE-COVID19. Brasília (DF): Ministério da Saúde. Secretaria de Vigilância em Saúde; 2020:17

11 Harmon AC, Cornelius DC, Amaral LM, Faulkner JL, Cunningham MW Jr, Wallace K, LaMarca B. The role of inflammation in the pathology of preeclampsia. Clin Sci (Lond). 2016;130(06): 409-419. Doi: $10.1042 / C S 20150702$

12 Poorolajal J, Jenabi E. The association between body mass index and preeclampsia: a meta-analysis. J Matern Fetal Neonatal Med. 2016;29(22):3670-3676. Doi: 10.3109/14767058.2016.1140738

13 Siddiqui A, Azria E, Howell EA, Deneux-Tharaux C; EPIMOMS Study Group. Associations between maternal obesity and severe maternal morbidity: Findings from the French EPIMOMS population-based study. Paediatr Perinat Epidemiol. 2019;33(01):7-16. Doi: $10.1111 /$ ppe. 12522

14 Zanette E, Parpinelli MA, Surita FG, Costa ML, Haddad SM, Sousa $\mathrm{MH}$, et al; Brazilian Network for Surveillance of Severe Maternal Morbidity Group. Maternal near miss and death among women with severe hypertensive disorders: a Brazilian multicenter surveillance study. Reprod Health. 2014;11(01):4. Doi: 10.1186/ 1742-4755-11-4

15 Mendoza M, Garcia-Ruiz I, Maiz N, Rodo C, Garcia-Manau P, Serrano B, et al. Pre-eclampsia-like syndrome induced by severe COVID-19: a prospective observational study. BJOG. 2020;x:x

16 Horta BL, Barros FC, Lima NP, Assunção MCF, Santos IS, Domingues MR, et al; Pelotas Cohorts Study Group. Maternal anthropometry: trends and inequalities in four population-based birth cohorts in Pelotas, Brazil, 1982-2015. Int J Epidemiol. 2019;48(Suppl 1): i26-i36. Doi: 10.1093/ije/dyy278

17 Pacagnella RC, Cecatti JG, Osis MJ, Souza JP. The role of delays in severe maternal morbidity and mortality: expanding the conceptual framework. Reprod Health Matters. 2012;20(39):155-163. Doi: 10.1016/S0968-8080(12)39601-8

18 Leal MDC, Esteves-Pereira AP, Viellas EF, Domingues RMSM, Gama SGND. Prenatal care in the Brazilian public health services. Rev Saude Publica. 2020;54:08. Doi: 10.11606/s1518-8787.202005 4001458

19 Bittencourt SD, Domingues RM, Reis LG, Ramos MM, Leal MD. Adequacy of public maternal care services in Brazil. Reprod Health. 2016;13(Suppl 3):120. Doi: 10.1186/s12978-016-0229-6

20 Roberton T, Carter ED, Chou VB, Stegmuller AR, Jackson BD, Tam Y, et al. Early estimates of the indirect effects of the COVID-19 pandemic on maternal and child mortality in low-income and middle-income countries: a modelling study. Lancet Glob Health. 2020;8(07):e901-e908. Doi: 10.1016/S2214-109X(20)30229-1 [ahead of print]

21 Boletim Epidemiológico. Brasília (DF): Ministério da Saúde. Secretaria de Vigilância em Saúde; 2020;51(20)

22 Khalil A, Hill R, Ladhani S, Pattisson K, O'Brien P. Severe acute respiratory syndrome coronavirus 2 in pregnancy: symptomatic pregnant women are only the tip of the iceberg. Am J Obstet Gynecol. 2020:S0002-9378(20)30529-9

23 Sutton D, Fuchs K, D’Alton M, Goffman D. Universal screening for SARS-CoV-2 in women admitted for delivery. N Engl J Med. 2020; 382(22):2163-2164. Doi: 10.1056/NEJMc2009316

24 Souza JP, Bellissimo-Rodrigues F, Santos LLD. Maternal mortality: an eco-social phenomenon that calls for systemic action. Rev Bras Ginecol Obstet. 2020;42(04):169-173. Doi: 10.1055/s-00401710041

25 Pacagnella RC, Nakamura-Pereira M, Gomes-Sponholz F, Aguiar RALP, Guerra GVQL, Diniz CSG, et al. Maternal mortality in Brazil: proposals and strategies for its reduction. Rev Bras Ginecol Obstet. 2018;40(09):501-506. Doi: 10.1055/s-0038-1672181 